\title{
The comparison of the efficacy of intra-peritoneal instillation along with local infiltration with bupivacaine versus placebo for post-operative analgesia after laparoscopic tubal ligation
}

\author{
Aniket S. Kakade, Naval Dudam, Tushar M. Panchanadikar*
}

Department of Obstetrics and Gynecology, Bharati Vidyapeeth (Deemed to be University) Medical College, Pune, Maharashtra, India

Received: 11 June 2019

Accepted: 03 July 2019

*Correspondence:

Dr. Tushar M. Panchanadikar,

E-mail: tushar.panchanadikar@gmail.com

Copyright: () the author(s), publisher and licensee Medip Academy. This is an open-access article distributed under the terms of the Creative Commons Attribution Non-Commercial License, which permits unrestricted non-commercial use, distribution, and reproduction in any medium, provided the original work is properly cited.

\begin{abstract}
Background: Intra-peritoneal instillation of local anesthetics has been shown to minimize post-operative pain after laparoscopic surgeries. The present study was undertaken with the following aim to compare the efficacy of intraperitoneal instillation and local infiltration with bupivacaine versus placebo for post-operative analgesia after laparoscopic tubal ligation. To correlate the advantages and side effects of the drugs during the procedure. To establish a protocol for the use of bupivacaine instillation and infiltration for post-operative analgesia after laparoscopic tubal ligation.

Methods: A prospective study was carried out in a tertiary care hospital attached to a teaching medical institute. Institutional ethics committee approval was obtained for this randomized control study (double blind) including 50 women who will be divided in two groups. Group A will be administered intra-peritoneal bupivacaine along with local infiltration. Group B will be administered normal saline. Post-operative pain will be monitored by a blind observer and rescue analgesia will be administered at visual analogue score of 3 .

Results: Both the groups were comparable with respect to age and BMI. The mean duration of analgesia in Group A with bupivacaine was $315.60 \pm 79.9$ min (Median $300 \mathrm{~min}$ ). The mean duration of analgesia in Group B with normal saline was $138.20 \pm 46.97 \mathrm{~min}$ (Median $150 \mathrm{~min}$, p value $<0.001$ ).

Conclusions: The study depicts a significant pain relief after use of bupivacaine. Bupivacaine instillation in the peritoneal cavity along with local infiltration of the drug gives prolongs pain relief as compared to normal saline.
\end{abstract}

Keywords: Analgesia, Intra-peritoneal bupivacaine, Laparoscopy, Local anesthesia, Post operative pain, Tubal ligation

\section{INTRODUCTION}

Intra-peritoneal instillation of local anaesthetics has been shown to minimise post-operative pain after laparoscopic surgeries. ${ }^{1,2}$ Pain after laparoscopic tubal ligation results from stretching of the intra-abdominal cavity, avascular necrosis of the fallopian tube loop, peritoneal inflammation, and diaphragmatic irritation caused by residual carbon-dioxide in the peritoneal cavity. ${ }^{1}$ Intraperitoneal instillation of bupivacaine and ropivacaine are used for postoperative analgesia after laparoscopic procedures. ${ }^{3}$ These are very effective and do not have any added risk for complications. Simultaneous instillation of local anaesthetic into the peritoneal cavity along with local infiltration alleviates the post-operative discomfort due to both the visceral and parietal component of the pain. ${ }^{4}$ 
With the help of this study we plan to study the efficacy of the use of bupivacaine locally and intra-peritoneal during laparoscopic tubal ligation.

\section{METHODS}

A double blind randomized prospective study was carried out in a tertiary care referral teaching hospital. Institutional ethics committee approval was obtained. 50 women who presented for laparoscopic tubal ligation and fulfill the inclusion criteria were recruited for the study.

\section{Inclusion criteria}

- All women who present for Laparoscopic tubal ligation in the study period.

\section{Exclusion criteria}

- Patient with any intra-operative complication like hematoma formation or avulsion of the fallopian tube and any allergy to used drug.

The study was carried out for a period of 9 months from September 2018 to May 2019. All the women were administered general anesthesia and had ASA I and II. The patients were randomized in two groups. Group A received intra-peritoneal instillation of $20 \mathrm{ml} 0.25 \%$ bupivacaine and local infiltration with $3 \mathrm{ml}$ bupivacaine per port site. Group B received intra-peritoneal instillation and local infiltration with normal saline.

Standard protocol for induction and maintenance of general anesthesia will be used for both the groups. Immediate post operative pain relief will be with intravenous fentanyl sodium at dose of $1 \mathrm{mcg} / \mathrm{kg}$. Both groups will not receive any other analgesia for postoperative pain.

Both the groups will be monitored by a blind observer for post-operative pain using the visual analogue scale (VAS). VAS will be assessed every 1 hour for 10 hours and rescue analgesia will be administered at VAS 3 by intramuscular diclofenac sodium $75 \mathrm{mg}$. The duration of analgesia and the time in hours for requirement of rescue analgesia was studied and compared using 'MannWhitney U test.

\section{RESULTS}

Total 50 patients were recruited in the study. 25 received bupivacaine and 25 received normal saline. Both the groups were comparable with the patient characteristics of height, weight and BMI (Table 1). There was no bias in the selection of patients with respect to their body composition.

Table 1: Profile of both groups.

\begin{tabular}{|llll|}
\hline \multirow{2}{*}{ Characteristic } & Mean \pm SD & & \\
& Group I bupivacaine study group (n=25) & Group II normal saline control group (n=25) & $\begin{array}{l}\text { P } \\
\text { value }\end{array}$ \\
\hline Height $(\mathrm{cms})$ & $153.00 \pm 4.39$ & $153.80 \pm 5.25$ & 0.562 \\
\hline Weight $(\mathrm{Kg})$ & $55.52 \pm 7.01$ & $57.48 \pm 6.60$ & 0.314 \\
\hline BMI & $23.66 \pm 2.59$ & $24.56 \pm 2.68$ & 0.233 \\
\hline
\end{tabular}

Table 2: Duration of analgesia.

\begin{tabular}{|lll|}
\hline & $\begin{array}{l}\text { Mean } \pm \text { SD } \\
\text { Group I bupivacaine study } \\
\text { group (n=25) }\end{array}$ & $\begin{array}{l}\text { Group II normal saline } \\
\text { control group (n=25) }\end{array}$ \\
\hline Mean duration of post-operative analgesia & $315.60 \pm 79.9 \mathrm{~min}$ & $138.20 \pm 46.97 \mathrm{~min}$ \\
\hline Median & $300 \mathrm{~min}$ & $150 \mathrm{~min}$ \\
\hline Q1 & $270 \mathrm{~min}$ & $120 \mathrm{~min}$ \\
\hline Q3 & $360 \mathrm{~min}$ & $180 \mathrm{~min}$ \\
\hline
\end{tabular}

The duration of post-operative analgesia (Table 2) after intra-peritoneal instillation and infiltration of bupivacaine was $315.60 \pm 79.9 \mathrm{~min}$, and was significantly prolonged analgesia as compared to normal saline group $138.20 \pm 46.97 \mathrm{~min}$. The Mann Whitney $U$ test of significance revealed a $\mathrm{p}$ value $<0.001$, the difference was statistically significant. The patients in the Group I who received bupivacaine had a pain relief for a significant duration and were more comfortable during their post-operative recovery period. Figure 1 depicts the graphical analysis of duration of analgesia in both the groups.

The study group involving bupivacaine had significant pain relief after the intra-peritoneal instillation and the local infiltration. There was no reported adverse effect with the use of bupivacaine and there were no complications. 


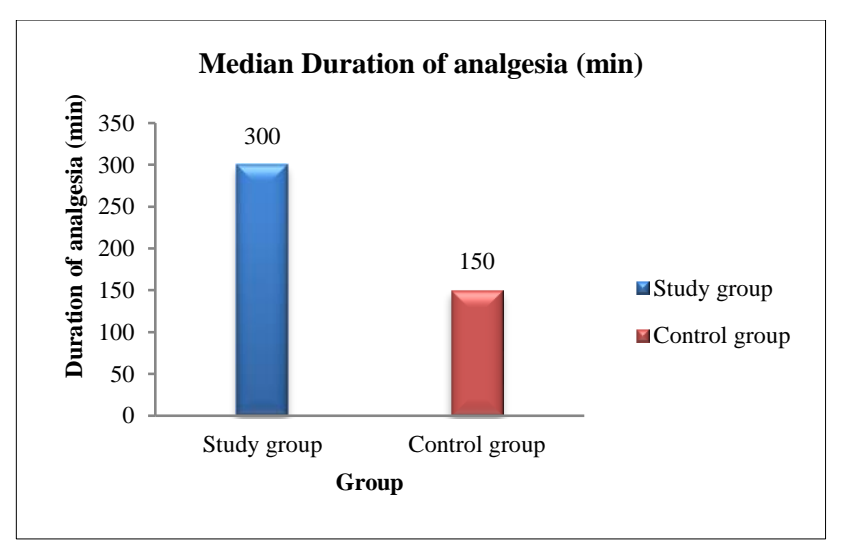

Figure 1: Graphical analysis of difference in duration of need of rescue analgesia.

\section{DISCUSSION}

Pain after laparoscopic surgery has many components with origin from the somatic and visceral afferents. Laparoscopic tubal ligation has added component of tubal ischemia leading to pain. Intra-peritoneal route of analgesia has been found to be effective after laparoscopic surgeries., ${ }^{5,6}$ Intra peritoneal instillation of local anesthetic along with local infiltration at the port site leads to more profound analgesia. ${ }^{3,7,8}$

Conventionally non-steroidal anti-inflammatory drugs (NSAIDs) are administered for post-operative pain relief. ${ }^{4,9,10}$ These drugs act centrally and have limited action on the pain arising from peritoneal irritation, tubal ischemia and diaphragmatic irritation. These drugs have side effects like nausea and vomiting if administered parentally. Although the volume of carbon-dioxide gas used for laparoscopic tubal ligation is less due to short duration of the procedure and the surgeon performs maneuvers to remove any residual gas from the abdomen at the end of the procedure, residual gas still accumulates under the diaphragm and cause peritoneal irritation leading to significant post-operative discomfort to the patient. ${ }^{4}$ Patients who received intra-peritoneal and local infiltration with bupivacaine had significant pain relief for $315.60 \pm 79.9 \mathrm{~min}$ (Median $300 \mathrm{~min}$ ) as compared to the group with normal saline 138.20 \pm 46.97 min (Median 150 min, $\mathrm{p}$ value $<0.001)$. Subjective assessment of the patients who received bupivacaine revealed that these patients were more comfortable after the surgery, had early ambulation and tolerated the surgery well as compared to the control counterparts.

\section{CONCLUSION}

Intra-peritoneal and local infiltration with bupivacaine has definitive beneficial effect for post-operative pain relief after laparoscopic tubal ligation. It should be administered as an additive to the conventional analgesia techniques and as a component of multimodal analgesia.

Funding: No funding sources

Conflict of interest: None declared

Ethical approval: The study was approved by the Institutional Ethics Committee

\section{REFERENCES}

1. Pati BK. Intraperitoneal analgesia for postoperative pain relief after laparoscopic gynaecological surgeries. Int $\mathbf{J}$ Reprod Contracept Obstet Gynecol. 2017;6:5099-102.

2. Das NT, Deshpande C. Effects of intraperitoneal local anaesthetics bupivacaine and ropivacaine versus placebo on postoperative pain after laparoscopic cholecystectomy: a randomised double blind study. J Clin Diagn Res. 2017;11:UC08-12.

3. Cruz JJ, Diebolder H, Dogan A, Mothes A, Rengsberger M, Hartmann M, et al. Combination of pre-emptive port-site and intraoperative intraperitoneal ropivacaine for reduction of postoperative pain: a prospective cohort study. Eur J Obstet Gynecol Reprod Biol. 2014;179:11-6.

4. Gibbison B, Kinsella SM. Postoperative analgesia for gynecological laparoscopy. Saudi J Anaesth. 2009;3:706.

5. Mathew BI, Thasleem AK, Venugopal V. Efficacy of intraperitoneal bupivacaine for postoperative analgesia. Int J Health Sci Res. 2016;6:63-7.

6. Moiniche S, Jorgensen H, Wetterslev J, Dahl JB. Local anesthetic infiltration for postoperative pain relief after laparoscopy: a qualitative and quantitative systematic review of intraperitoneal, port-site infiltration and mesosalpinx block. Anesth Analg. 2000;90:899-912.

7. Manjunath AP, Chhabra N, Girija S, Nair S. Pain relief in laparoscopic tubal ligation using intraperitoneal lignocaine: a double masked randomized controlled trial. Eu J Obstet Gynecol Repro Biol. 2012;165:110-4.

8. Goldstein A, Grimault P, Henique A. Preventing postoperative pain by local anesthetic instillation after laparoscopic gynecologic surgery: a placebo-controlled comparison of bupivacaine and ropivacaine. Anesth Analg. 2000;91:403-7.

9. Alexander JI. Pain after laparoscopy. Br J Anaesth. 1997;79:369-78.

10. Dreher J, Nemeth D, Limb R. Pain relief following day case laparoscopic tubal ligation with intra-peritoneal ropivacaine: a randomised double blind control study. Aus New Zealand J Obst Gynaecol. 2000;40:434-7.

Cite this article as: Kakade AS, Dudam N,

Panchanadikar TM. The comparison of the efficacy of intra-peritoneal instillation along with local infiltration with bupivacaine versus placebo for postoperative analgesia after laparoscopic tubal ligation. Int J Reprod Contracept Obstet Gynecol 2019;8:3268-70. 